\title{
Full title
}

Perspectives of day and accommodation services for people with enduring mental illness

Short title:

Perspectives on day and accommodation services

Wendy Bryant, MSc, DipCOT, Occupational Therapy Lecturer, Brunel University, London

Christine Craik, MPhil, DMS, DipCOT, MCMI, ILTM Director of Occupational Therapy, Brunel University, London

Elizabeth McKay, PhD, MSc, BSc (Hons), DipCOT, ILTM Formerly Course Leader MSc Occupational Therapy Brunel University. Now Head, Department of Occupational Therapy, School of Health Sciences, University of Limerick.

Corresponding author:

Wendy Bryant

Occupational Therapy Lecturer

Department of Health and Social Care

Brunel University

Osterley Campus

Borough Road

Isleworth

TW7 5DU

Telephone: 02088910121

Wendy.bryant@brunel.ac.uk 


\title{
Perspectives of day and accommodation services for people with enduring mental illness
}

\begin{abstract}
Background

This qualitative study analysed user, carer and staff perspectives on day and accommodation services for people with enduring mental illness in the London Borough of Hillingdon.
\end{abstract}

\section{Method}

Twelve focus groups, attended by 95 participants, were conducted by the independent research team and the data collected were subject to constant comparative analysis.

Findings Practical and strategic recommendations were generated for the funding agency. Day services were valued highly for preventing relapse and promoting independence. Users sought a more active role in developing opportunities in day and accommodation services and staff were believed to hold a pivotal role in offering ongoing support.

Conclusions In the area studied, facilitating discharge, managing risk and meeting shelter needs had been emphasised at the expense of user empowerment and access to meaningful occupation. Day and accommodation services enable users with enduring mental illness to achieve stability and increase independence, but are currently underresourced and undermined by wider service pressures.

Declarations of interest This study was funded by the Hillingdon Primary Care Trust and the London Borough of Hillingdon. There are no conflicts of interest. 
This article is a version after peer-review, with revisions having been made. In terms of appearance only this might not be the same as the published article.

Keywords: Day Care Centres; Empowerment; Housing; Mental Health Services

\section{INTRODUCTION}

The United Kingdom Government as part of its major initiative on assuring quality of services in the National Health Service (NHS) introduced a series of National Service Frameworks (NSF) which proposed national standards to be implemented at local level, taking account of local circumstances. In the NSF for Mental Health (Department of Health 1999), standard four states that effective services are required for people with enduring mental illness. In North West London, the London Borough of Hillingdon is responsible for providing mental health services for a population of around 260,000 people, through direct provision and through a number of voluntary organisations.

Payne et al (2000) in a study undertaken in Hillingdon explored users' and carers’ views of the NSF ( DOH 1999). Within this work, a range of opinions on day services were held by the participants with some highlighting the benefit of attending, while others felt they were "loose in the community". The authors made a number of recommendations for the local services including future surveys of users' views and increased user involvement in the development of services. As a result of this the Local Implementation Team for the NSF (DOH 1999) in Hillingdon commissioned independent research into perspectives of users, carers, staff and managers on day and accommodation services. A project team, comprising health and social care managers and a user empowerment officer, co-ordinated data collection via focus groups and validated the conclusions and recommendations of the independent research team. 
This article is a version after peer-review, with revisions having been made. In terms of appearance only this might not be the same as the published article.

The recommendations informed strategic planning and practical improvements to the service, with an emphasis on increased involvement of users in all aspects of service delivery in Hillingdon. However, the findings also have wider implications for services elsewhere.

\section{Day services}

Terms such as day service, day centre, day care or day treatment are sometimes used inconsistently in the UK mental health literature. Whatever term is used, the purpose of day services broadly covers prevention of admission, promotion of independence and ongoing support (Muijen 1993). There is overlap between service settings for these three roles. For examply, day treatment is most commonly associated with a clinical setting, with health professionals as staff and time-limited attendance. In a Cochrane systematic review, Marshall et al (2002) compared day hospitals with outpatient care and concluded there was little evidence of effectiveness for day treatment and no evidence to justify the provision of day care. However, this review was based on only eight studies, one dating back to 1966, and an average of nineteen years since publication. A second systematic review (Catty et al 2002) evaluated the effectiveness of non-medical day centres, concluding that there was insufficient evidence available. However, as these were Cochrane reviews, only randomised controlled trials could be considered, excluding qualitative studies. While randomised controlled trials are considered to be the gold standard for evaluating effectiveness of intervention being the highest level of evidence, there are alternative views on how effectiveness can be judged (Faulkner 2002). Catty et al conclude that there is no reason why randomised controlled trials could not be used to generate evidence in the day care sector. This 
This article is a version after peer-review, with revisions having been made. In terms of appearance only this might not be the same as the published article.

conclusion has to be challenged, given the ethical difficulties of implementing trials in a setting concerned with care rather than cure of symptoms (Faulkner 2002, Tanenbaum 2003). The original intention of Cochrane's call for evidenced based medicine was to divert funds wasted on ineffective medical treatment to the care of people whose difficulties were not responsive to medical treatment (Cochrane 1999). Indeed, the NSF in its recommendations for research and development identified the importance of involving service users and 'developing research tools with service users to assess their view on how services can best meet their needs’(DOH 1999:116).

The benefits of attending day services have been demonstrated in small studies such as Allen's (2000:22) report of a review of day services in Cambridgeshire. Here day services were highly valued by users who perceived them as having a "key role in preventing mental health deterioration” and having benefits over and above helping them move towards independent living. Users wanted greater access to services at weekends and more user-led services. Rollason et al (2000:20) described a collaborative study involving users and a project officer at a day centre in Birmingham. Users favoured planned activities but identified that withdrawal from these was necessary at times. They also highlighted the value of a "place to go". Importantly, both these reports highlighted that low key social activities were perceived as beneficial and therapeutic for the users.

This was reflected in the findings of Yurkovitch et al (1999), who contended that users sought to establish supportive networks to maintain their sense of control over their symptoms. Where staff actively facilitated users to develop strategies for self- 
This article is a version after peer-review, with revisions having been made. In terms of appearance only this might not be the same as the published article.

management, creating networks of support specific to each user, the day service appeared to be more successful. In contrast, a more general study by Martin et al (1999) illustrated that passive roles alienated users and staff. This study used multiple methods to examine community mental health services provided in Glasgow and concluded that, whilst users were satisfied with services in general, a lack of coherent joint working between staff groups prevented user empowerment, especially in relation to power and control over decisions.

Day services form a part of community mental health services, and Valios (2001) described how integrating day services with respite care, supported employment and assertive outreach provided flexible support. This project, in Cheshire, was strongly linked to supported accommodation, funded by the social care agency and staff included designated care staff to provide support at home.

These small scale studies focusing on user views suggest that day services are of value to the people who use them, in contrast to the Cochrane reviews which did not demonstrate this.

\section{Accommodation services}

In the UK a major report outlining Government policy, Supporting People (Office of the Deputy Prime Minister 2002) emphasised the importance of promoting independence while protecting vulnerable people. It recognised the need for individual care packages rather than the type of accommodation defining the level of care offered. Partnerships between social care, health care and housing providers are 
This article is a version after peer-review, with revisions having been made. In terms of appearance only this might not be the same as the published article.

encouraged to identify gaps in provision. Like the NSF (DOH 1999) this national policy framework was implemented locally, with geographic areas required to formulate a local 'Supporting People' strategy to secure funding for future developments.

Warren and Bell's (2000) Australian study, investigating user views of accommodation, concluded that users gave priority to privacy and safety, rejecting designated group homes because of associated stigma. Also in Australia the importance of housing in underpinning social integration and personal independence is emphasised (Moxham and Pegg 2000): the benefits of user involvement in housing provision is illustrated in a report by Bond (1999), describing a housing project funded by the voluntary sector.

There is an absence of evidence relating to the need for meaningful occupation for users with severe mental illness: as occupational therapists, the research team were aware of the benefits of occupation for health and the adverse effects of deprivation (Wilcock 1998).

\section{Aims}

To explore the perspectives of users, carers and staff on day and accommodation services for mental health service users.

To generate recommendations for strategic development and practical improvement of local services. 
This article is a version after peer-review, with revisions having been made. In terms of appearance only this might not be the same as the published article.

To contribute to the evidence base for the development of day and accommodation services for mental health service users.

\section{METHOD}

This qualitative study used focus group methodology to explore the views of users, carers and staff. A focus group is a semi-structured group session, held in an informal setting and moderated by a group leader, to collect personal experience and beliefs related to a designated topic (Morse, 1994). This research method acknowledges the expertise of the group members on a given topic and was therefore relevant for this study where the topic was perspectives of the day and accommodation services. A questioning route (Kruger and Casey 2000) was developed by the project team to structure the format of the groups.

Initial ethical approval for the study was obtained from Brunel University and then the Hillingdon Local Research Ethics Committee.

Users and carers were invited to participate via flyers and letters, while staff and managers were invited via letters. Day service users were defined as people who were using day services at the time of the study or who had been discharged from such services in the previous 12 months. Accommodation users were current residents in housing provided by local health, social and voluntary agencies. Staff and managers were those working in the identified locations at the time of the study. 
This article is a version after peer-review, with revisions having been made. In terms of appearance only this might not be the same as the published article.

\section{Day service focus groups}

Seven focus groups were held for this part of the study. Four focus groups were held for users; one in each of the three community mental health centres in the Borough and the fourth group at a voluntary sector day centre. One focus group was organised for staff and one for managers from across the Borough. The seventh focus group was for carers with a carers' support group providing the participants. The focus group was held at the usual venue for their meetings.

\section{Accommodation focus groups}

Five focus groups were held for this part of the study. The carers' support group also generated participants for the carers' focus group to evaluate accommodation services. One carer attended both groups. Three focus groups for users were held in communal areas of the accommodation settings being evaluated. The first was at a voluntary sector group home; the second was at a rehabilitation unit staffed by health professionals, close to the acute admission unit of the local hospital and the third group was held in a social services hostel. The fourth group was held at the voluntary sector day centre with users who lived in one person and two person flats.

\section{Procedure}

A written explanation of the study was provided to all participants, and explained in the introductory phase of each focus group. Signed consent was obtained after an opportunity to ask questions about the study. Anonymous demographic data were collected at the end of the focus group. Users and carers were given a $£ 10$ voucher for participation. 
The first author acted as facilitator for all groups with the second author cofacilitating the accommodation groups and the third author co-facilitating the day service groups. All focus groups were audio recorded on tapes and software. The seating positions of group members were recorded in field notes, with additional details, observations and reflections being added by the facilitators immediately after each group.

\section{Data Handling and Analysis Procedures}

The audiotapes were transcribed verbatim and the transcripts checked by the researchers for accuracy. The data were then subjected to constant comparative analysis to identify recurrent and contrasting aspects. These were further developed into categories and then constructed into a range of relevant themes grounded in the data. Each group was treated separately and then the findings compared and contrasted across the groups.

\section{FINDINGS}

Twelve focus groups were conducted during May - July 2002. The groups lasted from 50-90 minutes with some having a break halfway. Table one shows the number of people attending each category of group, their gender and length of contact with mental health services, as a service user, service worker or carer. There were many more people involved in each of the 7 day services focus groups $(n=72)$ than the 5 accommodation focus groups $(n=23)$. Twice as many women as men participated in 
This article is a version after peer-review, with revisions having been made. In terms of appearance only this might not be the same as the published article.

the groups, with the majority of service users and carers having been in contact with mental health services for over 5 years.

\section{Table 1}

Number of participants in each category of focus groups and gender and length of contact with mental health services of participants

\begin{tabular}{|l|c|c|c|l|l|l|l|}
\hline \multirow{2}{*}{ Focus Group } & \multicolumn{6}{|l|}{ Participants } & \multicolumn{4}{l|}{$\begin{array}{l}\text { Contact with/experience of mental } \\
\text { health services }\end{array}$} \\
\cline { 2 - 8 } & M & F & total & $\begin{array}{l}\text { Less } \\
\text { than 1 } \\
\text { year }\end{array}$ & $\begin{array}{l}1-5 \\
\text { years }\end{array}$ & $\begin{array}{l}5-10 \\
\text { years }\end{array}$ & $\begin{array}{l}10 \\
\text { years + }\end{array}$ \\
\hline DAY SERVICES & 16 & 23 & $\mathbf{3 9}$ & 4 & 9 & 6 & 18 \\
\hline Users & & & & & & & \\
\hline
\end{tabular}


This article is a version after peer-review, with revisions having been made. In terms of appearance only this might not be the same as the published article.

\begin{tabular}{|l|c|c|c|c|c|c|c|}
\hline Carers & 4 & 5 & $\mathbf{9}$ & 0 & 3 & 0 & 6 \\
\hline Managers & 2 & 7 & $\mathbf{9}$ & 0 & 0 & 1 & 8 \\
\hline Staff & 1 & 14 & $\mathbf{1 5}$ & 4 & 5 & 1 & 5 \\
\hline Totals & $\mathbf{2 3}$ & $\mathbf{4 9}$ & $\mathbf{7 2}$ & $\mathbf{8}$ & $\mathbf{1 7}$ & $\mathbf{8}$ & $\mathbf{3 7}$ \\
\hline ACCOMMODATION & & & & & & & \\
\hline Users & 7 & 7 & $\mathbf{1 4}$ & 2 & 2 & 2 & 8 \\
\hline Carers & 2 & 7 & $\mathbf{9}$ & 0 & 0 & 1 & 8 \\
\hline Totals & $\mathbf{9}$ & $\mathbf{1 4}$ & $\mathbf{2 3}$ & $\mathbf{2}$ & $\mathbf{2}$ & $\mathbf{3}$ & $\mathbf{1 6}$ \\
\hline Grand total & $\mathbf{3 2}$ & $\mathbf{6 3}$ & $\mathbf{9 5}$ & $\mathbf{1 0}$ & $\mathbf{1 9}$ & $\mathbf{1 1}$ & $\mathbf{5 3}$ \\
\hline
\end{tabular}

Table 2 shows the mean age of users in both parts of the study, which was in the early to mid fifties with a similar age range. The mean age of the carers in both part was 64, ten years older than the users.

Table 2

Age of users and carers

\begin{tabular}{|l|c|c|}
\hline Focus Group & $\begin{array}{c}\text { Age } \\
\text { Mean }\end{array}$ & $\begin{array}{c}\text { Age } \\
\text { Range }\end{array}$ \\
\hline Day Service Users & 51 & $28-76$ \\
\hline Day Service Carers & 64 & $42-75$ \\
\hline $\begin{array}{l}\text { Accommodation } \\
\text { Users }\end{array}$ & 55 & $26-71$ \\
\hline $\begin{array}{l}\text { Accommodation } \\
\text { Carers }\end{array}$ & 64 & $52-82$ \\
\hline
\end{tabular}


This article is a version after peer-review, with revisions having been made. In terms of appearance only this might not be the same as the published article.

\section{Day Services}

Service users and carers described experiences of how they accessed services and the process of assessment. Service provision was seen by many participants to encompass ongoing support, along with crisis prevention and management, although there was conflict between these roles. This conflict highlighted the need to develop core functions for day services. The potential for change at individual level was mirrored by a drive to implement changes at service level, with users and managers generating suggestions for change. The staff and managers were keen to incorporate other services into the overall picture, whether drawing on examples of good practice beyond the local area, or developing local networks of support. Finally, it was recognised that, for many users, stability and independent living were realistic goals, with or without the ongoing support of services.

\section{Accommodation services}

As with the day services, these findings suggest that, there was a lack of clarity about the core function of each accommodation setting and the services overall, reflecting the number of accommodation providers across the health, social and voluntary sector. Staff skills were recognised as a key resource in the support offered to users, which was at different levels in different locations. Users and carers were particularly concerned about issues of safety and accessibility. There appeared to be an absence of meaningful occupation for tenants and residents, especially where users were 
unable to easily access local community services and there was no encouragement by staff.to do so.

The key elements common to both aspects of the study were:

- defining services

- $\quad$ supporting service users effectively

- improving services

- meaningful occupation

\section{Defining services}

Elements of day services, such as opportunities to meet other users and access activities and cheap food, were valued by those involved. However, the lack of clarity about the role of day services beyond practical aspects led to confusion for users, staff and managers. For instance, users of day services found they received conflicting messages about their attendance:

"At the beginning we were told ... come in as often as possible. We start coming in as often as possible and then somebody says, "You're getting a bit too dependent on this." So you're not sure. You think ... am I dependent? ”

This inconsistency was apparent between the services in different locations:

“All the day services have a different manager so they're obviously operating in slightly different ways ... it's hard to give that message to other clients if you're giving another message to some clients.” 
This article is a version after peer-review, with revisions having been made. In terms of appearance only this might not be the same as the published article.

Managers also believed that it was difficult to provide an adequate service in the circumstances. They accepted that they were attempting to meet many different needs, such as ongoing support for some users, involving others in supported employment or specific intervention while at the same time containing others who were acutely ill. It was evident that some users did not receive a service because they did not have the organisational skills to make use of what was on offer. One carer describing day services noted that:

“The structured ones are too structured... if she doesn't turn up on time she is told it's too late to come in, whereas ... she might have great problems getting herself there."

The core functions of accommodation services were location based: the rehabilitation hostel had an emphasis on skills gain:

“... you are helped to cook, get back on your feet and establish yourself and get back into a routine."

Another hostel was a place were users waited for permanent placement elsewhere, leading to a feeling of desperation, with one resident noting that :

"Well if there is something that comes up then I'll take it to get out of here. Anybody can move out. I'm desperate really."

Carers were concerned that the accommodation offered was inappropriate and in one instance a carer reported that:

"He lives in my house all the time and nobody can get him to go into this flat because he absolutely hates it because he is in with a lot of elderly people.” 
This article is a version after peer-review, with revisions having been made. In terms of appearance only this might not be the same as the published article.

The diversity of individual need was appreciated, but as long as core functions were defined by location rather than assessed need, it would seem impossible to meet the demand for support:

"everybody is so individual. ... so many different factors to cover"

Even where there was a shared need, such as at the group home where users were experiencing difficulties in physically accessing parts of the home, it remained unaddressed. One user noted that increasing disability might mean that she would have to move out of her current accommodation:

"I would have to move out into some residential care I suppose, that's what worries me."

Some users believed that living with enduring mental illness made living anywhere difficult:

“There doesn't seem to be anywhere to go to make you feel different. ... It's something that's descended in you."

\section{Supporting service users effectively}

Users were generally positive about the services provided by the voluntary sector. Those in accommodation were supported by support workers who visited weekly, resolving practical difficulties and working to prevent relapse:

“...you are not very well she will see you a couple of times a week or take you to the shops ... or give you a meal.”

Voluntary sector day services were valued for the non-judgemental approach of the staff, although there was concern as to whether staff without professional training were equipped to work effectively with users, especially in acute episodes. Carers in 
This article is a version after peer-review, with revisions having been made. In terms of appearance only this might not be the same as the published article.

the accommodation focus group believed that more training for all staff was required, to ensure support was given:

“ they need proper training to deal with mental patients."

They felt their relatives were not being supervised adequately citing occasions where difficult behaviour was not addressed:

“... he's carried on those bad habits ... not getting washed, not doing his work, not changing his bed and to hell with the bills"

Emphasis on crisis management took staff time away from ongoing services reinforcing the difficulties of staff attempting to cope with conflicting demands. In day services, groups would be cancelled; and within the accommodation services, there was an absence of support for independence in domestic activities, leisure, education and work. This was despite the key role of frontline staff in day and accommodation services in providing specific support for individuals to prevent relapse and promote independence. This led to users believing that they had to have a crisis in order to gain staff attention as their requests for additional support were repeatedly ignored:

"And when I was ill last time, I tried to explain to my key worker that I was ill. No one would believe me"

Staff reported that shortage of permanent staff resulted in vacancies and that the consequent dependency on agency staff to cover these vacancies increased their caseload and disrupted ongoing work with users. One member of staff stated that:

"I don't have enough time to give them what I'd like to if we were fully staffed.”

The impact of staff changes was also recognised by users; 
This article is a version after peer-review, with revisions having been made. In terms of appearance only this might not be the same as the published article.

“You get comfortable with somebody ... sometimes the position isn't filled so you got to wait and wait and then you have to start again and it's not so easy to keep going”

Staff were frustrated with what they perceived as a lack of medical support in managing and preventing crises, and they felt that doctors did not value their opinion:

"Because you work in a day programme so you are nothing, you don't know what you are talking about. They don't realise that you are the one dealing with the actual client."

There was a mechanistic view of day services from one user:

"I am part of the productivity in a sense, I come here and the doctors do their job, their assessments, their work to you, and you're like a product, you're on a conveyor belt. You go on the conveyor belt and you're sent out again and you come back.”

\section{Improving services}

All focus group participants knew the services could be improved and there were many suggestions of how this could be achieved. Carers sought greater recognition for their role in supporting users, often a critical one when a user was in transition between services and users also acknowledged this:

"My daughter was with me, giving me support, someone to lean on, someone to be there, ... I wouldn't have done it without her." User 
Staff and managers were aware of the achievements of services in other areas, and felt that potential was being wasted in their services. Managers were also aware of the increasing demands on day services to provide an alternative to inpatient care and facilitate early discharge: "We've got good ideas, we are trying to develop things but it is very piecemeal and it's not co-ordinated."

Managers took a broad view of what could be achieved:

"I think ... it would be a community network where people can be maintained, have their social network, be much more empowered about what they're doing. It would be about people having their acute needs being met in a specific way.” Manager

Users wanted a more active role in organising services and suggested that: "there must be some way of, of us being less passive and more responsible.”

\section{Meaningful occupation}

Participants in both parts of the study identified the need for meaningful occupation. However, accommodation service users reported that staff did not take an active role in facilitating progress to recovery or stability through occupation:

“they didn't really get involved. It was just they stayed in the office really. We were just left to our own devices.”

This view was also shared by carers who noted the limited role of the staff:

"All they do for him is they wash his clothes, feed him and give him medication they don't tell him to do anything else." Carer

Even when there was an emphasis on rehabilitation, this was not sustained over time, with users in one setting observing that the opportunities to shop for food for 
This article is a version after peer-review, with revisions having been made. In terms of appearance only this might not be the same as the published article.

themselves had stopped: " we were just going out with the staff and then the staff seemed to go and get it [shopping].”

In the group home, the users had lived together for many years and particularly valued the efforts of staff to organise activities:

"When someone else worked here temporarily we had a game of Bingo and 3 of us enjoyed doing it and it gives you something to get up and do for instead of just laying down .... It makes you motivated.”

Day service users emphasised the benefits of attendance in a general sense, structuring their day and supporting them as they worked towards goals beyond the service itself: Staff recognised the core role of day services in enabling users to establish enduring social networks:

' 'Gives them a meeting area where they can meet people in the same situations and they swap stories and they help each other as well. They form their own network of support for the other hours that we don't cover."

Users believed that group work gave staff the opportunity to gain increased understanding of the users' difficulties:

"if they had a bit more groups where they can help people to deal with certain different things. Perhaps they might understand more”. Day services were predominantly based within community mental health centres, although there was evidence that some new services were based in non-clinical settings, for example a batik group and a women's group. Users who had experience of more than one service particularly valued weekend and evening services, many of which were provided by the voluntary sector with a diverse range of activities. 
This article is a version after peer-review, with revisions having been made. In terms of appearance only this might not be the same as the published article.

\section{DISCUSSION}

The focus groups gave participants the opportunity to share and compare their experiences and perspectives, expressing positive views in addition to frustrations with the services and suggestions for improvements. In particular, the focus groups enabled users to express their views in a supportive environment and this may have contributed to the large number of participants. The smaller number of users of accommodation services willing to participate may have been influenced by their reluctance to offer negative opinions about the accommodation in which they lived. In contrast, the carers were more critical of the services although they recognised the challenges of providing services for people with enduring mental illness. In retrospect, conducting the accommodation focus groups in a more neutral location might have improved the response rate for that part of the study. Alternatively, consulting with study participants on an individual basis may have helped with issues of confidentiality.

Overall, the large number of participants was a particular strength for this type of qualitative study. The extensive data encompassed a diverse range of views expressed by the different groups of participants. However, clear themes emerged which reflected the findings of other similar studies (Yurkovitch et al 1999, Bond 1999, Allen 2000, Rollason et al 2000, Martin et al 2000) but were in contrast to the Cochrane reviews (Marshall et al, 2002, Catty et al 2002). This may in part be explained by one of the themes identified in this study; the lack of clear definition of the services studied. It is evident that despite this lack of definition, users and carers 
This article is a version after peer-review, with revisions having been made. In terms of appearance only this might not be the same as the published article.

valued the services provided although they were able to articulate their shortcomings and suggest methods of overcoming them. Moreover, staff and managers also expressed their frustration at this lack of a clear purpose. Core recommendations for both aspects of the study emphasised the need to state the scope and purpose of the services, to inform development in relation to other services and future evaluation. It is possible that evaluation could involve randomised controlled trials, thus in theory generating evidence for effectiveness. However, the requirements of the NSF to listen to users' views may be in contrast to this more traditional view of evaluating services, and the pressure to develop local services in response to those views would most likely take precedence over large scale evaluation.

It was evident to all participants that crisis management was prioritised by staff over the maintenance aspects of the service or even rehabilitation which might assist users move out of services. This was reflected in the views of staff who were critical of medical staff who, at the time of the study, seemed not to value their opinion on how users coped with everyday occupations. Thus staff could be considered to devalue the occupations which users and carers valued and through which they envisaged a way out of dependence. Furthermore, users recognised that the 'conveyor belt' approach of staff was not appropriate for preventing relapse and maintenance of abilities. This may also partly explain why users and carers wanted more power over their treatment, recognising the need to make it more relevant to their needs.

The study was conducted in one location in London and produced recommendations for the services there. Although there is the potential for focus groups to be dominated 
This article is a version after peer-review, with revisions having been made. In terms of appearance only this might not be the same as the published article.

by particular views, care was taken in conducting the groups and in the analysis to minimise this. Some of the findings were specific to the local setting, other themes have wider relevance. With this qualitative study, there was no attempt to ensure that those who responded to the invitation to participate in this study were representative of a larger population and in some respects they could be dismissed as a convenience sample not worthy of having their views listened to. However, that would be to negate the authority of their opinions as users of the service and participants in its delivery. The NSF (DOH 1999) respects their views and actively encourages their acquisition.

It was clear from this study that all groups of participants had valuable opinions on the current provision of services and relevant suggestions for improving them. In particular, it is imperative to ensure users have means of negotiating their own care packages via the Care Programme Approach and have means of influencing the configuration and provision of services (Bond 1999). Not only do they have views but they are also keen to be involved in the change process and are aware of how they could be facilitated to do so reflecting the views of the users in Martin et al's (1999) study.

In this study, both day services and accommodation services provided a low key, but vital, role in both preventing relapse and facilitating long term stability and independence for a diverse group of users. Day services were seen to provide a safe place which supported users through difficult times and motivated them to structure their day: “That's what it gives you, a goal, because if you never had it to come to you 
This article is a version after peer-review, with revisions having been made. In terms of appearance only this might not be the same as the published article.

wouldn't get up anyway" They believed that by attending and becoming involved in activities they could prevent relapse and readmission.

"I'd simply be doing nothing ... and I'd be down even more."

"We are all afraid of going back in hospital again."

This echoes the findings of Allen (2000) and Rollason et al (2000). However, this valuable function does not seem to be fully recognised in the overall lack of clarity of the roles provided by these services. It could be argued that it is this low key role which is most appreciated by users but least acknowledged by staff.

This apparent lack of understanding by staff of the needs of users may be indicative of staff shortages, staff changes and consequent dependence on the frequently changing unskilled agency staff which may directly impact on user well-being. All participants recognised that staff skills in supporting users were central to the success of services and that there was a need for improved staff training. Focusing this around encouraging user participation could benefit users and staff (Martin et al 1999).

The model of providing day services within the community mental health centres and the location of one of the accommodation services in close proximity to the acute admissions unit appears to emphasise clinical and professional input: however, the aspect users valued highly was the informal support from each other and opportunity for meaningful occupation, with the back up of staff when required.

Many users and carers recognised that being involved in everyday occupations like shopping, bingo and group activities was beneficial to them and met their needs 
This article is a version after peer-review, with revisions having been made. In terms of appearance only this might not be the same as the published article.

beyond those of safety and shelter. Residents at the rehabilitation unit valued the opportunity to regain skills within a supported environment:

“...you are helped to cook, get back on your feet and establish yourself and get back into a routine and just so you can get on."

It was believed that users could achieve stability and independence in the long term through engaging in activities and roles, enabling them to cope with the difficulties which may have required them to seek support in the first place. The emphasis on the therapeutic value of meaningful occupation suggests a key role for occupational therapists in the provision of day and accommodation services and in training other staff to function effectively in these areas. But, it also calls into questions the value given to occupational therapy by mental health services as a whole.

\section{CONCLUSION}

This study has responded to the NSF (DOH 1999) by listening to users, carers, staff and managers to obtain their views of services, using qualitative methods. Their responses indicate that day services and supported accommodation are valuable resources in the ongoing care and support of people with enduring mental illness. The question remains, however, whether service providers choose to listen to the evidence of this and other small scale qualitative studies, which together question the stated preference for evidence from RCTs. Future development of services could be shaped and enhanced by an inclusive approach to the evidence available and strategies for evaluating effectiveness. 


\section{REFERENCES}

Allen, M. (2000). An underrated service. Community Care. 14 December 2000:22

Bond H (1999) An opportunity for independence. Community Care 6 May 1999:267

Catty, J., Burns, T. \& Comas, A. (2002). Day Centres for severe mental illness. The Cochrane Database of Systematic Reviews, Issue One.

Cochrane A L (1999) Effectiveness and efficiency: random reflections on health services. London, Royal Society of Medicine Press Ltd

Department of Health (1999) National Service Framework for Mental Health. Executive Summary. London, The Stationery Office.

Faulkner A, Thomas P (2002) User-led research and evidence-based medicine. The British Journal of Psychiatry 180:1-3

Krueger R, Casey M A (2000) Focus Groups. $3^{\text {rd }}$ Edition. London, Sage Publications.

Marshall, M., Crowther, R., Almaraz-Serrano A.M. \& Tyrer, P. (2002). Day hospital versus out-patient care for psychiatric disorders. The Cochrane Database of Systematic Reviews, Issue One.

Martin C, de Caestecker L, Hunter R, Gilloran A, Allsobrook S, Jones L (1999). Developing community mental health services: an evaluation of Glasgow's mental health resource centres. Health and Social Care in the Community 7(1):51-60

Morse, J.M. (1994). Critical issues in qualitative research methods. Thousand Oaks. Sage.

Moxham L, Pegg S (2000) Permanent and stable housing for individuals living with a mental illness in the community: A paradigm shift in attitude for mental health nurses. Australian and New Zealand Journal of Mental Health Nursing 8:82-88

Muijen M (1993) Mental health services: what works? In Weller M, Muijen M (eds) Dimensions of community mental health care. London WB Saunders, Chapter 3:38-61

Office of the Deputy Prime Minister (2002) Supporting People 
http://www.supporting-people.odpm.gov.uk, accessed $6^{\text {th }}$ December 2002

Payne, F., Schofield, P. \& O’ Gorman, C. (2000). Taking soundings: Users' and carers' views of the national Service Framework for Mental Health in Hillingdon. London: Immediate Access Project.

Rollason, K., Stow, J. \& Paul, J. (2000). People in the smoke room. Community Care, 14 December 2000: 20-1

Sainsbury Centre for Mental Health (2000) The capable practitioner. London, The Sainsbury Centre for Mental Health.

Spicker, P., Anderson, I., Freeman, R. \& McGlip, R. (1995). Pathways through psychiatric care: The experience of psychiatric patients. Health and Social Care in the community, 3 (6); 343-52.

Tanenbaum S (2003) Evdence-based practice in mental health: practical weaknesses meet political strengths. Journal of Evaluation in Clinical Practice 9(2): 287-301

Valios N (2001) Catering for mental health users. Community Care, May $10^{\text {th }}, 32-3$

Warren R, Bell P (2000) An exploratory investigation into the housing preferences of consumers of mental health services. Australian and New Zealand Journal of Mental Health Nursing. 9:195-202

Wilcock A (1998) An occupational perspective of health. New Jersey, SLACK Inc. Chapter 6: Ill Health: Occupational Risk Factors

Yurkovich E, Smyer T, Dean L (1999) Maintaining health: proactive client-oriented community day treatment centres for the chronic mentally ill. Journal of Psychiatric and Mental Health Nursing 6:61-69 